\title{
Perspectives on Early Childhood Education in Romania: a Qualitative Research
}

\section{Anca Egerau, Ramona Lile, Alina Roman, Gabriela Kelemen, Dana Rad, Tiberiu Dughi, Evelina Balas}

Early childhood education and care (ECEC) is a concept that refers to the period from the birth of the infant to the time when the child begins the kindergarten. In children's lives, it is a significant time because it is when they first learn how to connect with others, including friends, teachers and parents, and often continue to build passions that will stick with them throughout their existences. It is a period when children develop essential social and emotional skills and a bond is built between the infant, their parents and the teacher. Representative program no. 1 - Increasing access to ECEC under the ESL Strategy aims to implement the following key measures: (i) a coherent framework for ECEC; (ii) involvement of the family (with children 0-3 years) in parental education programs and by providing financial incentives; (iii) qualification, training and retention of early education and care staff. The non-competitive Early Inclusive and Quality Education project, implemented by the Ministry of National Education in partnership with the University of Pitesti, Aurel Vlaicu University of Arad and Stefan cel Mare University of Suceava, between 2019 and 2021, aims to implement measures provided in the Representative Program no.1 of the early school leaving Strategy. In the first year of implementation, it is envisaged to develop a diagnostic framework document on the organization and operation of quality services in the field of early education in Romania and to support their implementation in the future. In this context, 8 focus groups are planned to take place in each development region, in order to outline a SWOT analysis of the educational, medical and social services provided in early education in Romania in the last 3 years. This report presents the findings from two focus groups that were organised in Arad and Bistrita by Aurel Vlaicu University of Arad.

Keywords: early childhood education, Romania, focus group, qualitative research. 


\section{Introduction}

Early childhood education and care (ECEC) is a concept that refers to the period from the birth of the infant to the time when the child begins the kindergarten. In children's lives, it is a significant time because it is when they first learn how to connect with others, including friends, teachers and parents, and often continue to build passions that will stick with them throughout their existences. It is a period when children develop essential social and emotional skills and a bond is built between the infant, their parents and the teacher.

Efficient, sustainable and equitable development will be the foundation of the future of Europe: enhancing the quality and productivity of education systems across the EU is essential to all three of these growth parameters (Holdena, Linnerudb, Banister, D., 2014).

In this sense, Early Childhood Education and Care (ECEC) is the foundation of lifelong learning progress, social inclusion, professional growth and, consequently, vocational integration capability. Complementing the primary role of the family, ECECs have an important and lasting impact, impossible to achieve without further measures (Egerău, 2020). The children's first experiences form the basis of their entire further training. If a strong base is set in the early years, further schooling is more successful and more likely to last a lifetime, decreasing the likelihood of early school leaving, increasing equality in education and reducing the cost to government as a result of the lack of expertise and investment in the social, health and even judiciary systems (Peleman, Lazzari, Budginaitè, Siarova, Hauari, Peeters, Cameron, 2018)

ECEC systems have the potential to offer a good start in the future for all young people and to break the loop that transmits inter-generational drawbacks.

There are very diverse benefits of high quality ECEC services: social, economic and educational. In setting the groundwork for better skills for future EU people, ECEC services play a crucial role in enabling us to face the mid- and long-term challenges and to build a more trained workforce capable of responding to and adapting to technological change (Sundqvist, 2020). There is ample evidence that admission to high-quality ECEC systems results in far improved outcomes for international core competency assessments, such as PISA and PIRLS, which are equal to success in one or two academic years (Zhao, 2020).

The existence of high quality ECEC services allows parents to more successfully reconcile family responsibilities with professional ones, thus improving their capacity for professional integration. They assist children 
not only in their future schooling, but also in their social integration, creating well-being and adding to their professional integration as adults (Moser, Melhuish, Edward, Petrogiannis, Pastori, Slot, Leseman, 2014).

For children with vulnerable socioeconomic groups, especially those from migrant or low-income households, ECEC programs are often extremely valuable. They will help to raise children out of poverty and the tough family climate, thus leading to the achievement of the Europe 2020 Poverty Reduction Flagship Initiative objectives.

By enabling all children to exploit their potential and giving them the means to do so, qualitative ECEC services for pre-school children can go a long way towards achieving two of the key objectives of the Europe 2020 strategy, namely reducing the early school leaving rate below $10 \%$ and removing at least 20 million people from the prospect of poverty and social exclusion.

Access to inclusive, high quality and universally accessible ECEC is welcoming to everyone. In addition to helping children exploit their own potential, they will also assist parents and other members of the family by taking part in similar steps to enhance employment opportunities, vocational training, and parental education and leisure time. Parental education would focus on a better acceptance of individuality of each child, on stimulating a positive perceptions of child personality characteristique, on understanding of parental roles with theirs responsibilities, on importance of emotional sharing in family (Dughi, 2014; Dughi, Roman, 2008; Roman, Pinto, 2015).

ECEC is a planned and goal-oriented educational, training and care organization with an emphasis on pedagogy, as defined by the law. The three dimensions form an intertwined whole aimed at facilitating the learning and overall well-being of the infant.

According to the age of the infant and the circumstance, the measurements are stressed differently. During the child's day in ECEC, teaching and guidance are incorporated in various circumstances and tasks.

In 2018, The National Core Curriculum (NCC) for ECEC outlines domains of learning that identify major aims and content of pedagogical practices.

The learning domains are separated into five categories:

- The diverse language ecosystem

- Diverse ways of saying

- Me and our community

- Exploring and engaging with my world

- I grow, move and evolve. 


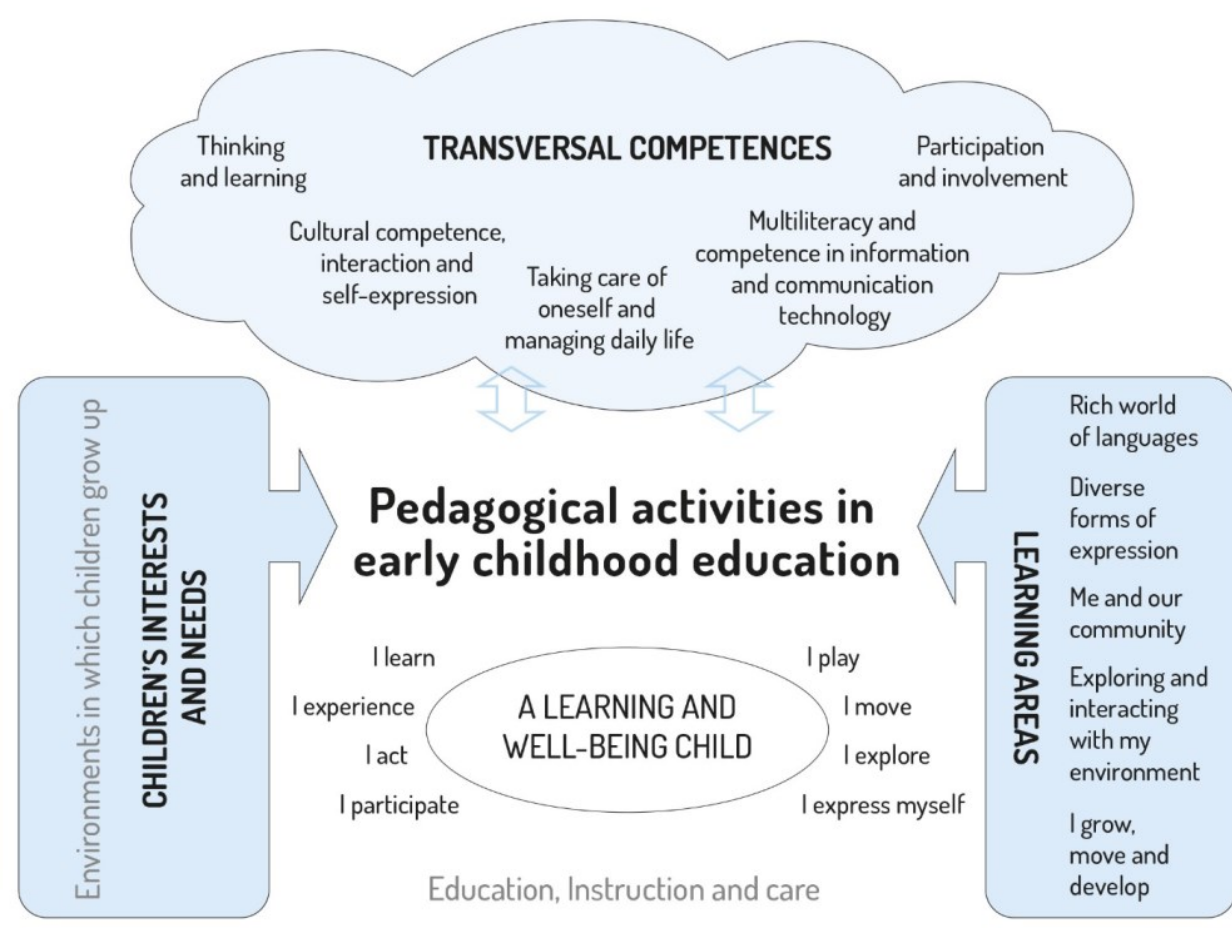

\section{Operational culture Learning environments Working methods Cooperation Pedagogical documentation Evaluation and development UNDERLYING VALUES CONCEPTION OF LEARNING}

Fig. 1. The framework for pedagogical activities in ECEC (Source: European Commission, EACEA National Policies Platform, Eurydice https://eacea.ec.europa.eu/national-policies/eurydice/content/teaching-andlearning-early-childhood-education-and-care-other-pre-primary-education tr)

Instead of being approached as independent bodies, the themes of various areas of education are integrated and adapted according to the needs and competence of the children. The preferences and queries of children serve as a central concept for preparing and conducting the learning activities.

A main aim of the ECEC is to improve the transversal competencies of children. Knowledge, abilities, values, attitudes and will are part of transversal competence. The development of transversal competence facilitates the growth of children as adults and responsible participants to culture and community. 
Five integrated areas of expertise are specified by the national core curriculum for ECEC, depicted in Figure 1:

- Thought and studying

- Cultural abilities, communication and self-expression

- Caring after oneself and handling everyday life

- Multiliteracy and ICT competence

- Engagement and interest.

The goals and content of the areas of learning and the didactic system, as specified in the NCC, direct professionals in the preparation and implementation, along with children, of flexible and integrative pedagogical activities. The goals set for the ECEC and the age, expectations, prerequisites and desires of children are impacted by the selection processes. The professionals guide infants in classes of various styles to experiment with and use different operating processes.

The core curriculum emphasizes flexible and practical working approaches that facilitate children's imagination, engagement and involvement. Children are empowered, with all their senses and their whole body, to express freely, pose questions, solve the situation together and explore the reality. People need to foster positive emotions in themselves and those who surround them, not only as an ends to themselves, but also as a means to achieving growth and improved long-term physical and psychological well-being (Nave, Roman, 2019).

\section{Context}

The adoption of the Strategy on reducing early school leaving (ESL) in Romania in June 2015 was a condition for accessing funding from the European Social Fund for the 2014-2020 programming period.

Representative program no. 1 - Increasing access to ECEC under the ESL Strategy aims to implement the following key measures: (i) a coherent framework for ECEC; (ii) involvement of the family (with children $0-3$ years) in parental education programs and by providing financial incentives; (iii) qualification, training and retention of early education and care staff. These measures aim to expand access to early education services, prevent dropout and thus reduce the rate of early school leaving from $18.1 \%$ in 2017 to $11.3 \%$ by 2020 .

In 2003, Romania was 17.8 percent behind the European Union (EU) average in terms of participation in education and early care, managing to reduce this gap, so that now it is only 7.3 percent behind. 


\begin{tabular}{|l|c|c|c|}
\hline \multicolumn{1}{|c|}{ Indicator } & $\begin{array}{c}\text { Reference } \\
2013\end{array}$ & $\begin{array}{c}\text { Actual } \\
2017\end{array}$ & $\begin{array}{c}\text { Target } \\
2020\end{array}$ \\
\hline $\begin{array}{l}\text { Gross enrollment rate for pre-school } \\
\text { education }\end{array}$ & $2,7 \%$ & $3.41 \%$ & $23.3 \%$ \\
\hline Gross coverage rate for the 0-5 age group & $43,0 \%$ & $46,7 \%$ & $58.5 \%$ \\
\hline
\end{tabular}

According to the Report of the National Institute of Statistics, the National Education System - synthetic data from 2017, in Romania there are 351 nurseries, of which $96.3 \%$ are financed from public funds. There are a total of 18,719 children enrolled, most of them with a ten-hour extended program $(88.4 \%)$.

The non-competitive Early Inclusive and Quality Education project, implemented by the Ministry of National Education in partnership with the University of Piteşti, Aurel Vlaicu University of Arad and Ştefan cel Mare University of Suceava, between 2019 and 2021, aims to implement measures provided in the Representative Program no.1 of the ESL Strategy, presented above, and, as a result, sets as its general objective - Development of the national operational framework in the field of preschool education, for infants under the age of three in kindergarten, to promote access to schooling.

The success of children's acquisitions and personality development is deeply affected by the quality of the educational environment. That is why we will insist on creating a good physical, psychological and social environment in child care and preschool institutions. An optimal learning environment is interactive, stimulating and safe, reflecting the children's diverse identities and needs. This environment must be flexible and can be changed according to the topics addressed and the interests of the child. Teachers organize the environment according to learning objectives ensuring the children's physical and mental safety, an educational environment that effectively contributes to their development. Interacting within the team develops different relationships among children, between children and adults, in which the emphasis is on the development of positive relationships, collaboration, acceptance, support and participation (Kelemen, 2020).

In the first year of implementation, it is envisaged to develop a diagnostic framework document on the organization and operation of quality services in the field of early education in Romania and to support their implementation in the future. In this context, 8 focus groups are 
planned to take place in each development region, in order to outline a SWOT analysis of the educational, medical and social services provided in early education in Romania in the last 3 years.

Bodies with responsibilities in the field of early preschool education and interested professionals are invited to participate in these focus groups: MMJS, ANPDCA, MS, DSP, MDRAPFE, MEN-ISE-ARACIP, ISJ / ISMB, CJRAE / CMBRAE, CCD, professional associations, nongovernmental organizations with relevant experience in the field, EICP teaching staff, parents, other interested representatives of civil society and public opinion.

\section{Focus Groups analysis}

\section{Organization and participants}

This report presents the findings from two focus groups that were organised in Arad and Bistrita by Aurel Vlaicu University of Arad. The first focus group was organised in Arad, on 23rd of July 2020 and it was moderated by Assoc.Prof.PhD Anca Egerau, Assoc.Prof.PhD Tiberiu Dughi and Assoc.Prof.PhD Evelina Balas. The second focus group was organised in Bistrita, on 31st of July 2020 and it was moderated by Prof.PhD Alina Roman, Prof.PhD Gabriela Kelemen and Assoc.Prof.PhD Dana Rad. Both focus groups gathered 40 participants and lasted for 90 minutes, starting at 11:30 in the morning, after the arriving and registration of the participants.

In Figure 2, we have depicted a procentual reprezentation of Romanian Counties from wich stakelorders participated: Arad (22\%), CaraşSeverin (8\%), Hunedoara (8\%), Sălaj (8\%), Bihor (6\%), Timiş (6\%), Mureş (5\%), Bistrița Năsăud (19\%), Cluj (5\%), Maramureş (5\%), and Satu Mare $(8 \%)$.

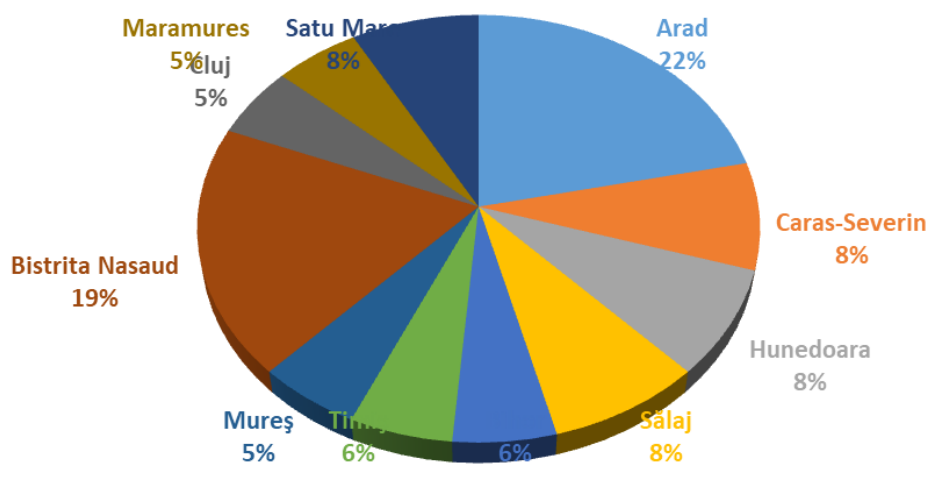

Fig. 2. Romanian Counties from wich stakelorders participated 
In Figure 3, we have depicted the type of stakeholder participants: County School Inspectorate (29\%), local administration (18\%), Nongovernmental organizations (6\%), and early childhood personnel (47\%).

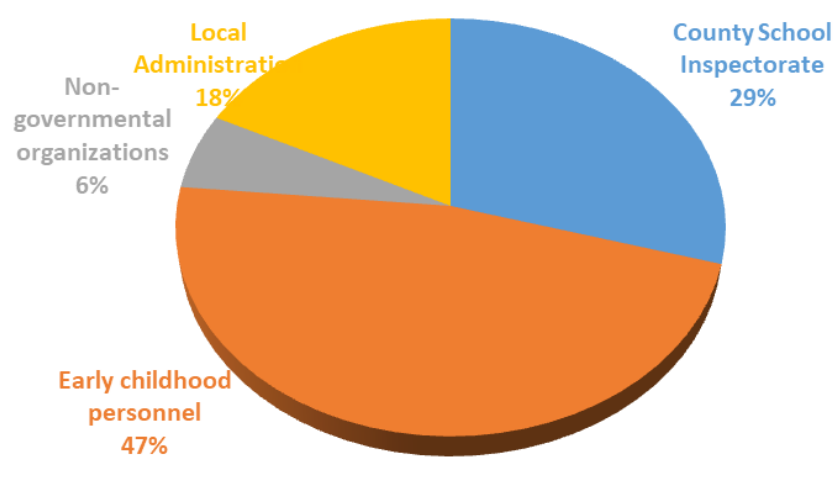

Fig. 3. Type of stakeholder participants

As these focus groups took place under COVID-19 pandemic restrictions, organizers and participants strictly conformed to all safety regulations.

\section{Methodology and qualitative analysis}

The focus group is considered a way of gathering verbal information, through a series of pre-formulated questions, addressed to several people who interact in order to find out what people think and feel about a particular topic. The focus group is a way to listen to people and learn from them, creating a permanent communication between the moderator and the participants, as well as between the participants (Balas, 2008).

Conducting focus groups (FG) comprisied the following stages:

- Presentation of the moderators - explanation of the purpose and objectives of the analysis, description of the method by which the participants were selected, presentation of the institution under which the FG is implemented.

- Presentation of the participants in the FG and their agreement regarding the recording of the meeting.

- Specifying the rules of FG.

- Asking the 5 standard questions according to the FG guide.

- Registering participants' answers.

- Summarizing the FG responses and conclusions. 
An introductory question was asked for the introduction: «What is the first word that comes to your mind when you hear the phrase «Early Childhood Education and Care"?

Below we present the most significant categories of answers received.

Early Childhood Education and Care (ECEC) as a FUTURE - a prosperous future that facilitates community development, the well-being of families receiving services, a relief of the community and families by developing these services, the child between 0 and 3 years is a serious problem of the community, rather during the period of 2-3 years, being the period in which the parent no longer benefits from parental leave and maybe not even a safe place to take him, in which to benefit from a professional care.

PRIORITY AND INVOLVEMENT - ECEC needs to become a support for future preschoolers.

IMPORTANCE - preschool is a very important period because at this age, between 0 and 3 years the child assimilates extraordinarily much knowledge, skills, abilities, and the role of teachers, educators in this period is a priority. The role of the educator is that of creator of souls, of modeler of behaviors which lays the foundations of later education.

BRICK - ECEC is a brick at the bay of a pyramid, the pyramid representing the life of a child who will become an adult. It is essential how we form it, the nursery representing the moment when the child enters society. It is important to train educators, to know how to be human, because in this age group children need great closeness, a soul connection.

FACT - all children are born with a potential to develop, to become someone. The idea of developing under the rule of education and early education is what makes the difference and can help children become adults and follow their own path. Their chances are higher if the influence starts as early as possible, from birth. It is crucial to refocus our attention on early education, to recover what has been left aside, and to do everything so that future generations can benefit from quality early education, so that the chances of children to become good people through education needs to be a priority.

FOUNDATION - ECEC is the cornerstone of education in which the child develops physically and morally and behaviorally, is a modeling stage.

REAL NEED - to provide care, love and empathy. Unfortunately, the participants point out that the nurseries do not have qualified staff in this field, at this time there are only medical and care staff, there are many vacant childcare educator positions, due to lack of qualified staff. ET is extremely 
necessary, constituting the child's first contacts in an organized setting. Entering the nursery is the basis for stepping into life, here you learn some basic skills. There are many children who, when entering the community, did not have the skills to eat alone, to sit on the potty. We conclude that there is a great need for qualified staff in the field of ECEC.

ECEC, whether it takes place in the nursery, kindergarten or family, has a decisive role in the development of the young child's brain, which will have an impact on life.

DIVERSITY - in terms of the educational needs and expectations of families, these are different issues as well as children's access to education, no matter what environment they belong to.

PROFESSIONALISM - by professional ECEC we refer to the formation of children's hygienic-sanitary skills, acquisitions that remain for life.

BEGINNING - participants recall that they took steps to set up pre-school groups and hit the legislative framework, so although there are kindergartens where groups of pre-school students could be set up, the activity could not be started due to legislative impediments, ECEC not constituting the essential care of the legislators.

1. Please decide on the type of system that Romania should opt for: a unitary system (children from birth to 6 years in the same type of institution, with the governance of a central authority, as system leader) or a fragmented system (different institutions for children under 3 years and for those over 3 years, with a different governance, taking into account the services currently offered to children aged from birth to 6 years in Romania, but also the fact that at European level we are witnessing a real resettlement of early education systems and their compatibility with a unitary set of quality standards?

Participants advocate for a unitary system, because the needs of ECEC are central and given the interests of many institutions, NGOs or individuals, there is a risk that some children will be left out or treated differently. The idea that there are still some institutions that cannot understand the needs of early education, a system in which children are protected, is emphasized. Rather than deciding on various institutions with different interests, the state should ensure a unitary policy in which there are financial and administrative measures and a coordination of ECEC programs, as is the case in pre-school education. Of course there are partnerships with certain institutions in the form of support and contributions, there must certainly be a clear policy for all children. There is a risk that some will be overprotected, favored, causing the phenomenon of positive discrimination and obviously negative discrimination. 
Participants argue that policies should protect children and not private interests. The nurseries should offer services with qualified medical staff in the care segment, and the educational part should be subordinated to the inspectorates. Regardless of the organization, there must be an interinstitutional collaboration, for the main beneficiary of the services to be the child. The teaching staff, the one who ensures the early education part, must be subordinated to the education system, being necessary a special training in this respect. Thus, the optimal model is a hybrid, between the medicalsanitary staff and the educational one.

It is necessary to have a legislative framework that allows entities other than those currently existing to organize nurseries, or early education, separately, thus there is a need to fragment services. The importance of the existence of a common framework regulating the curriculum part, legislation, nominative acts, qualitative standards as well as the supervision and monitoring part is underlined.

According to the nursery law of 2011 with application norms, the nursery is a social care and supervision service subordinated to the Social Assistance Directorate. Nurseries are also subordinated to the law of education, on the pre-school education side, which should be achieved through those childcare educators, who are methodologically coordinated by the management of the kindergarten under which the nursery operates, because most nurseries operate in the same building as the kindergarten. On the supervision and care side, there are medical and nursing staff. From 2018, after the last changes, it is provided the possibility of establishing private nurseries that may exist separately from the tutelage of the public authority.

Municipalities and large cities manage to finance and keep children in the nursery, the formulas being few and not at all common, but there are many communes that have space and qualified staff, who could take over some of these services.

The unitary legislation is also essential the subordination to the Ministry of Education, services financed entirely from the state budget, because otherwise there will be prejudices and obstacles. It is necessary for the authorities to be able to intervene and control the ECEC services, and thus provide unitary access to these fundamental rights. The 0-3 year old segment was left out, considering that it is the responsibility of the parent, but the parent can no longer cope with the lucrative demands and yet, there is a lack of professionalism to start the child alive.

Referring to the FINANCING part, here is a link between everything that means public institutions. Communities that have preschool 
education can expand the potential of kindergartens and include the age group $0-3$ years, although it is a huge responsibility.

It is recalled that Romania signed a document at the level of the European Commission in which it undertook to align the platform of early education with European standards, so the policy must be unitary. It is the state that must guarantee the right to education of all children and cannot militate to give fragmented responsibilities to other entities, because there will be no control and guarantee that all children will have access to quality services. The state must enter into its responsibilities and provide education for all children, unitary curriculum and unitary financing. Successful models in rural areas where we see the involvement of private actors in the financial support of nurseries are also based on interest, because companies are interested in parents of children from 0 to 3 years to work, thus creating these conditions, financing the nursery system.

In conclusion, it is important to bring points of view that guarantee the right to early education and the obligation of the state to meet its curriculum and funding commitments, and in particular, each community will participate, depending on existing resources.

2. What kind of services do you think should be offered to children from birth to 6 years?, only standard services - nursery and kindergarten type, only alternative services - type play centers, toy library, family kindergarten, etc. or standard and alternative services, depending on different needs identified at Community level.

The participants in FG mentioned various forms of services, but the variant of nurseries as providers of education and care services was highlighted the most. The need for coherent, planned educational services to double care services was emphasized, regardless of the type of institution responsible for early education.

There are currently care and education services, although parents and the community want much more. For example, health services, medical services, parental education services, personal development. Communities are different, so needs are different, so services need to be different. At the base there must be basic services: care, education, health, food, then these services to diversify according to the community and identified needs.

3. What are the categories of staff involved in ECEC, the level of education required for them and the institution (s) responsible for the initial and continuing training of staff involved in ECEC? 
The following are mentioned in the categories of staff: educators, childcare workers, carers - as permanent employees and nurse, psychologist, psycho-pedagogue, social worker - as service providers on request or depending on the specifics of the institution providing services for early education. On the 0-3 years segment, there are currently medical staff and educational staff. Up to the age of 3 , the emphasis should be on care, then on education, keeping this dual formula.

Regarding the educational part, the educational staff in ECEC should have the same qualification as the staff in kindergartens, so a unitary initial training is required on the age segment 0-6 years. This training must be provided by the Ministry of Education, and nurseries and kindergartens must select staff according to certain precise competencies. As for the care staff, those nurseries specializing in nursery and kindergarten, the staff should be based on health training. The importance of on-the-job qualification is emphasized, in-house training followed by on-the-job certification.

4. How do you see the process of outlining flexible training routes for ECEC teaching staff, in the context of current legislative provisions and the real need for the system?

Continuous training, with credits, in the field of providing care and / or educational services is considered necessary. They can be provided by universities or accredited NGO structures.

Regarding the flexible education routes, the necessity of the existence of the graduation diploma of a Pedagogical High School, or the completion of higher studies in the field of primary and preschool pedagogy, and in addition courses, internships and mentoring, to the free organization of the institution.

5. Please mention some verbs that should be present in the tools for monitoring and evaluating ECEC services.

Verbs reffered by participants are: to document, evaluate, ensure, identify, analyze, formulate, assist, correct, improve, guide, satisfy, care for, stimulate, protect, and develop.

\section{Conclusions}

The pre-school period is the point at which schooling will more effectively impact the growth of infants and can annihilate the effects of 
unfavorable social conditions. Research indicates that poverty and a disadvantaged family environment are most closely linked to poor school performance. There are also significant differences between children from wealthy and poor socioeconomic backgrounds at the age of 3 in cognitive, social and emotional progress, differences that appear to escalate by the age of 5 if not remedied. Studies conducted in the USA show that the positive effect of ECEC programs is twice as significant for children from disadvantaged communities as it is for children from wealthy socioeconomic backgrounds (Melhuish, 2004). Therefore, ECEC programs are especially valuable for children and their families from vulnerable socioeconomic backgrounds, including refugees and minorities (Melhuish, 2011). The advantages of ECEC programs, however, reach well beyond the socioeconomic scale, beyond disadvantaged conditions and can lead to addressing a variety of educational challenges in all social groups in a more sustainable and less wasteful manner than subsequent interventions (Nores, Barnett, 2010).

Closely linked to disadvantaged socio-economic backgrounds, ECEC is an important means of reducing the incidence of early school leave.

Differences in social growth and literacy skills among children from disadvantaged social backgrounds may be removed by highly available, highquality ECEC programs, thereby interrupting the cycle of low school success and discouragement, frequently leading to early school leaving and so on, in the transition of poverty from one generation to the next (Archambault, Côté, Raynault, 2020).

The data indicate that, on the whole, the school results of children from migrant families are very different from those of local children, that the second generation performs worse than the first generation in many Member States and that the drop-out rate of these children it is, on average, twice as large as that of native children (Vesely, 2013). Migrant families are also not acquainted with the host country's language and education system, so they may face specific difficulties in promoting the education of their children. There is compelling evidence that access to ECEC services can be a huge benefit for migrant children's cognitive and linguistic development. Traditional curricula in the United States have had especially positive impacts on subsequent school success and wages, but also in terms of criminal behaviour (Vesely, 2013). To enhance their school maturity and encourage them to start with their peers fairly, it is necessary to offer early language assistance to children with a different mother tongue (Egerău, 2019).

The case of the Roma minority, for example, is much more complicated and the majority of Member States face structural challenges in 
supplying Roma children with sufficient educational opportunities. Their participation rates in ECEC programs are typically much smaller than those of the local community, while their support requirements are greater, and raising these rates is a crucial strategic priority across the EU. As shown by ongoing pilot projects on Roma integration in some Member States with a financial commitment from the EU budget, ECEC facilities will play a key role in closing school gaps for Roma children (Khalfaoui, García-Carrión, Villardón-Gallego, 2020).

With respect to children with special needs, by acceding to the United Nations Convention on the Rights of People with Disabilities, the Member States have dedicated themselves to working toward the school inclusion of all children with special needs (Odom, Buysse, Soukakou, 2011). However, about $2 \%$ of the European school population still attends different institutions. The programs of ECEC include a platform to strengthen the inclusion of children with special educational needs and pave the way for their greater integration into public schools.

The capacity of ECEC services to overcome the above-mentioned integration issues depends on the proper architecture and financing of the ECEC structure. Clear proof exists that comprehensive access to affordable ECEC facilities is more useful than initiatives addressing disadvantaged people only. «Tailor-made» ECEC schemes are risky and, in fact, it is impossible to classify the target population with precision because of the possibility of stigmatizing their users and even prejudice in the latter stages of education. Also, tailor-made services are more likely than universal services to be cancelled.

ECEC programs can only partly compensate for family insecurity and socio-economic challenges, no matter how good their efficiency is. In order to improve the long-term viability of high-quality ECEC programs for children from deprived communities, these services need to be linked, within the scope of a holistic plan to interventions in other fields of action. Unit cost per child in ECEC services can be at least twice as high as in school education, especially if services are of high quality, but evidence indicates that in the long run they can be more cost-effective. In other words, higher spending in pre-school education will contribute to more savings (Yoshikawa, Weiland, Brooks-Gunn, Burchinal, Espinosa, Gormley, Ludwig, Magnuson, Phillips, \& Zaslow (2013). However, public expenditure on the pre-school training of children is smaller in most Member States than at any other time.

There are quite varied types of ECEC financing in the Member States, focused on public and private sources. The schooling and welfare of preschool children over 3 years of age is funded or co-financed by all European 
countries from public sources; less than half of the Member States fund any of the expenses without the need for family donations. Funding continues to typically be from private sources for children under 3. Some Member States are providing direct financial support, additional personnel and financial benefits for the retention of staff in the programs offered to groups at risk.

In view of the increased political attention paid by the Member States to the education and care of preschool children and the consequences of budgetary constraints, it is imperative that the funds be used as effectively as possible. Private services limit public spending and offer parents a wider range of options and increased control; however, they must not restrict everyone's access to high-quality services. Low-income families are generally the ones most in need of care for preschool children and at the lowest possible prices, but many of them cannot afford to entrust their children to private ECEC facilities.

To completely address the cognitive, mental, social and physical needs of all children, ECEC programs should be planned and delivered. These needs vary considerably from those of older school-age children. Practice analysis has shown that pimary years of children's lives are the most formative. This is the stage at which they learn the main habits and ways of life that will characterize them for life.

In the preschool age, the development of non-cognitive abilities (such as perseverance, motivation, desire to communicate with others) is important for successful academic ability and effective social integration, so ECEC curricula need to be applied beyond cognitive learning to incorporate socialization and a variety of non-cognitive facets. There must also be an association between care and schooling, whether or not the scheme is split between (a) care services from birth to 3 years of age and (b) pre-school education from 3 years of age to school age, and whether it is based on a unitary model spanning all ages from birth to compulsory school age.

Staff skills are important for the provision of high quality ECEC services. Attraction, training and development of adequately trained personnel is a big obstacle. Trends in the convergence of childcare and education accentuate the professionalism of ECEC staff, with a broader and higher selection of required levels of education, higher pay, improved working standards, but the general profile of staff remains very diverseThere is also a temptation to attribute «educational» practice to trained staff and to the «care» of less qualified staff, which also contributes to a lack of consistency in the care and education of the infant. Moreover, the multiplicity of tasks of ECEC practitioners and the variety of children they work with need a permanent reflection on pedagogical methods as well as a thorough contribution to professionalization. 
Training of people dealing with young at risk is an important part of initial training in many countries, but many other facets of diversity are not adequately taken into account. In comparison, employees in ECEC systems seldom profit from the same educational opportunities for on-the-job adaptation and on-the-job preparation as educators. Thus, while the professionalization and specialization of this employees has advanced in many Member States, it is beginning from a very low level in many countries and the improvement of this situation will form a significant part of the growth of ECEC services.

There is a topic of gender equity amongst the workers of the ECEC. Much of the personnel is female. It has been a matter of interest for a long time. Several countries have set quotas for the recruiting of male workers in ECEC services or have tried to redefine the occupation in order to minimize gender inequalities (Heikkilä, M., 2020). There is an immediate need to boost the attractiveness of men in the ECEC sector in all EU countries. Quality ECEC services deliver long-term results, which means that they must serve as the basis for higher levels of the education system so that children do not lose the benefits they have gained.

Systemic approach to ECEC programs implies close coordination between various fields of intervention, such as education, employment, health and social policy. These approaches make it simpler and more efficient for policymakers to coordinate and manage strategies and to pool resources for the good of children and their families. It calls for a coherent vision, shared by all stakeholders, including parents, of a similar structure for action across the system, with the same goals and roles and explicitly specified obligations at central and local level. This strategy also helps ECEC programs to adapt better to local needs. Exchanges of tactics and collaboration at EU level will allow countries to benefit from each other's best practices in this critical challenge.

For example, a smooth transition from one institution to another, from pre-school to primary school, involves clear coordination between levels as well as consistency of content and expectations. In addition, the growing demographic complexity in the EU and the challenge of reconciling radically diverse socio-cultural backgrounds increase the importance of the transition from family to ECEC programs and between different age classes within the same organization.

Mechanisms to guarantee the standard of ECEC programs can generally be focused on an established pedagogical system spanning the whole period between birth and compulsory school age. Such a structure is larger than a classical school curriculum. It may describe the competency requirements of the personnel, the guidance and pedagogical criteria and the 
legislative system to be adopted by the services involved. It can also set goals that can help child growth tracking, based on cooperation with parents and ECEC staff, to promote their progress at higher levels of education. Frameworks may set consistent specifications in the framework, from which outcomes can be calculated and quality assurance arrangements applied.

ECEC systems have an important role to play in minimizing early school leaving, so key issues and potential strategies in this field should be addressed in the national policy initiatives to meet the goals of the Europe 2020 strategy. There is an immediate need to share good practice and expertise around the EU in order to increase the consistency of ECEC regulation.

\section{References}

Archambault, J., Côté, D. \& Raynault, M. (2020). Early Childhood Education and Care Access for Children from Disadvantaged Backgrounds: Using a Framework to Guide Intervention. Early Childhood Educ J 48, 345-352, https://doi.org/10.1007/s10643-019-01002-x.

Balaş, E. (2008). Focus grupul în cercetarea psihopedagogică, în Roman Alina (coord), Educație, cercetare şi dezvoltare. Demersuri aplicative în şcoală, Ed. Universităţii Aurel Vlaicu, Arad.

Dughi, T. (2014). Consiliere educațională. Abordări aplicative, Editura Eikon, Cluj Napoca.

Dughi, T., Roman, A. F. (2008). Dimensiuni psihologice ale invățării, Editura Universităţii Aurel Vlaicu, Arad.

Egerău, A. (2019). Opinions of future teachers regarding the implementation of new education in school, Educația Plus 26 (1), 394-402.

Egerău, A. (2019). The development of metacognitive competences in the process of learning Romanian language and literature, Journal Plus Education, 136-140.

European Commission, EACEA National Policies Platform, Eurydice https://eacea.ec.europa.eu/national-policies/eurydice/content/teachingand-learning-early-childhood-education-and-care-other-pre-primaryeducation $\mathrm{tr}$ )

Heikkilä, M. (2020). Gender equality work in preschools and early childhood education settings in the Nordic countries - an empirically based illustration. Palgrave Commun 6, 75, https://doi.org/10.1057/s41599-020-0459-7.

Holdena, E., Linnerudb, K., Banister, D. (2014). Sustainable development: Our Common Future revisited, Global Environmental Change, Volume 26, 130-139, https://doi.org/10.1016/j.gloenvcha.2014.04.006.

Kelemen, G. (2020). Developing early childhood education competences (Early childhood education and care, ECEC), Journal Plus Education, Vol 27, No 2. $10.24250 / \mathrm{JPE} / 2 / 2020 / \mathrm{GK}$. 
Khalfaoui, A., García-Carrión, R., Villardón-Gallego, L. (2020). Bridging the gap: engaging Roma and migrant families in early childhood education through trust-based relationships, European Early Childhood Education Research Journal, 28:5, 701-711, DOI: 10.1080/1350293X.2020.1817241.

Melhuish, E. C. (2004). A literature review of the impact of early years provision on young children, with emphasis given to children from disadvantaged backgrounds. London: Institute for the Study of Children, Families \& Social Issues.

Melhuish, E. C. (2011). Education. Preschool matters. Science, 333(6040), 299-300. doi: $10.1126 /$ science.1209459.

Moser, T. Melhuish, Edward, C., Petrogiannis, K., Pastori, G., Slot, P., Leseman, P. (2014) Initial framework for evaluating and monitoring ECEC quality and wellbeing. Working Paper. Utrecht, The Netherlands.

Nave, T., Roman, A.F., (2019). Positive thinking is the name of the game, European Proceedings of Social and Behavioural Sciences, ERD, DOI: 10.15405/epsbs.2020.06.12.

Nores, M., Barnett, W. S. (2010). Benefits of early childhood interventions across the world: (Under) Investing in the very young. Econ. Educ. Rev. 29, 271 282.

Odom, S. L., Buysse, V. A., \& Soukakou, E. (2011). Inclusion for young children with disabilities: A quarter century of research perspectives. Journal of Early Intervention, 33(4), 344-356.347

Peleman, B., Lazzari, A., Budginaite, I., Siarova, H., Hauari, H., Peeters, J., Cameron, C. (2018). Continuous professional development and ECEC quality: Findings from a European systematic literature review, European Journal of Education, Volume 53, Issue 1, https://doi.org/10.1111/ejed.12257.

Roman, A. F., Pinto. M. L. C. (2015). Parental values and children's attitude towards reading, Procedia-Social and Behavioral Sciences 197, 939-943.

Sundqvist, P. (2020). Technological knowledge in early childhood education: provision by staff of learning opportunities. Int J Technol Des Educ 30, 225-242, https://doi.org/10.1007/s10798-019-09500-0.

Vesely, C. K. (2013). Low-income African and Latina immigrant mothers' selection of early childhood care and education (ECCE): Considering the complexity of cultural and structural influences. Early Childhood Research Quarterly, 28(3), 470-486. https://doi.org/10.1016/j.ecresq.2013.02.001.

Yoshikawa, H., Weiland, C., Brooks-Gunn, J., Burchinal, M., Espinosa, L., Gormley, W. T., Ludwig, J., Magnuson, K., Phillips, D., \& Zaslow, M. (2013). Investing in Our Future: The Evidence Base on Preschool, Society for Research in Child Development. Washington, D.C. 
Mariia Oliinyk, Otilia Clipa, Małgorzata Stawiak-Ososińska (editors)

Zhao, Y. (2020). Two decades of havoc: A synthesis of criticism against PISA.J

Educ Change 21, 245-266, https://doi.org/10.1007/s10833-019-09367-x. 